Insight, part of a Special Feature on Catastrophic Thresholds, Perspectives, Definitions, and Applications

\title{
Panarchy: Discontinuities Reveal Similarities in the Dynamic System Structure of Ecological and Social Systems
}

\author{
$\underline{\text { Ahjond S. Garmestani }}^{1}{ }^{1} \underline{\text { Craig R. Allen }}^{2}$, and Lance Gunderson $^{3}$
}

\begin{abstract}
In this paper, we review the empirical evidence of discontinuous distributions in complex systems within the context of panarchy theory and discuss the significance of discontinuities for understanding emergent properties such as resilience. Over specific spatial-temporal scale ranges, complex systems can configure in a variety of regimes, each defined by a characteristic set of self-organized structures and processes. A system may remain within a regime or dramatically shift to another regime. Understanding the drivers of regime shifts has provided critical insight into system structure and resilience. Although analyses of regime shifts have tended to focus on the system level, new evidence suggests that the same system behaviors operate within scales. In essence, complex systems exhibit multiple dynamic regimes nested within the larger system, each of which operates at a particular scale. Discrete size classes observed in variables in complex systems are evidence of these multiple regimes within complex systems, and the discontinuities between size classes indicate changes in scale.
\end{abstract}

Key Words: panarchy; discontinuities; complex systems; regime shifts; resilience

\section{INTRODUCTION}

Ecosystems and human systems exhibit complex dynamics. Different explanations abound to account for such complexity. Some argue that dynamics emerge from interactions among variables at different scales and are not regulated by a central controller (Bak et al. 1988, Loreto et al. 1995, Bonabeau 1998). The dynamics of complex systems arise in a decentralized manner via interactions among agents, variables, and the system itself (Bonabeau 1998). Some describe such dynamics as self-organization, i.e., the ability of a system to configure itself regardless of initial conditions (Crutchfield 1994). Complexity theory, however, tends to ignore or downplay scale, which has been recognized by ecologists as critical to explaining complex dynamics (Holling 1992). Selforganization manifests in structures that appear at a larger scale as the result of interactions between smaller-scale variables (Bonabeau 1998). Selforganized systems are characterized by the ability of the system to adapt, which leads to broad-scale responses within the system (Hartvigsen et al. 1998). The development of pattern is a consequence of self-organization in complex systems (Levin 1998). As these patterns manifest, they entrain interactions between variables and agents that influence future system development (Levin 1998). Complex systems are resilient, because they appear to resist change or change slowly despite the interchange and evolution of individual components and the relationships between these components (Levin 1998).

Particular system states or regimes are defined at specific scales of space and time. In ecological systems, forests occupy spaces ranging from meters to thousands of kilometers and up to centuries of time. Within these scale ranges, temporal and spatial changes occur. A model of this phenomenon is the adaptive cycle (Fig. 1), in which the temporal changes of a system proceed through phases of growth $(r)$, conservation $(k)$, release $(\Omega)$, and reorganization ( $\alpha$; Holling 1986). An adaptive cycle describes the process of development and decay in a system (Holling and Gunderson 2002). The brief initial stage of development, the $r$ stage, consists of the rapid exploitation and garnering of resources by system components. This is followed by a $k$ stage 
of longer duration characterized by the accumulation of capital or other system elements or energies and by increasing connectivity and rigidity that eventually lead to a loss of resilience and the collapse of the system. The $\Omega$ stage of collapse is rapid and unleashes the energy accumulated and stored during the $k$ phase. The $\Omega$ phase is followed by reorganization during the $\alpha$ phase, a relatively rapid period of assembly of components. For example, as forests develop over decades, growth processes contribute to structural changes that make the system more vulnerable to change from smallerand larger-scale processes. The interaction of variables, e.g., drought, lightning strikes, and fuel accumulations, leads to phases of release such as forest fires, followed by periods of reorganization and regrowth. It is at the stage of reorganization that the system can shift regimes into a new or different configuration.

Panarchy theory was developed to explain crossscale dynamics of this type. A panarchy is a nested set of adaptive cycles operating at discrete scales (Gunderson and Holling 2001; Fig. 2). It recognizes that there are periods in time and connections across space at which systems at different scales are disjointed. These disconnects or disjuncts between scale regimes are present in complex systems (Holling 1992). Discontinuities are thresholds between the dynamic levels, i.e., adaptive cycles, of a panarchy (Holling and Gunderson 2001). Discontinuities are manifest in key cross-scale variables. They can appear as gaps in rank-order distributions of variables in complex systems, such as animal body masses in ecosystems or city size over a historical period. These size classes, i.e., basins of attraction, reflect the scales of opportunity available in a given system (Garmestani et al. 2007). Biota, including humans, interact with the environment at distinct scales and create selfreinforcing patterns resistant to change (Peterson 2002). The multiple but distinct scales of selforganization and the distribution of function within and across the scales create resilient systems (Peterson et al. 1998).

In this paper we review evidence for discontinuous attributes in ecological systems and in social systems. We argue that scale-dependent processes manifest in scale-dependent patterns in both types of systems. As such, these metrics are indicative of any complex adaptive system. Specifically, our goal is to advance our understanding of panarchy in complex systems by characterizing the discontinuities that separate discrete size classes of variables in complex systems. We begin by reviewing the crossscale explanations for regime shifts in complex systems. We follow that with a literature review of discontinuous attributes in ecological systems and in social systems, and end with a synthesis of the evidence for panarchy from complex systems.

\section{REGIME SHIFTS IN COMPLEX SYSTEMS}

Complex systems exhibit multiple dynamic regimes (Fath et al. 2003). The range of possible movements within a dynamic regime that can occur without generating a bifurcation is the domain of attraction (Ludwig et al. 2002). A system may remain within a particular dynamic regime or shift to another regime via small, continuous or large, discontinuous changes (Scheffer et al. 2001). With respect to ecosystems, a large body of literature on ecological resilience has emerged from studies of regime shifts in lakes, coral reefs, oceans, forests, and arid landscapes (Scheffer et al. 2001). As Scheffer and Carpenter (2003) have noted, it would seem that regime shifts should be largely driven by external perturbations to a system. In reality, however, both external and internal conditions can influence a system and cause it to reach a critical threshold that results in system reorganization (Holling 1973). Folke et al. (2004) found evidence that regime shifts were most likely to occur when ecosystem resilience had been reduced by removing functional groups and associated response diversity, as well as trophic levels, and by altering the magnitude, frequency, and duration of disturbance regimes.

In economic systems, endogenous economic growth depends upon infrastructure investment that likely lowers transportation costs, increasing the degree of linkage among agents (Rosser 2003). Researchers have found evidence for increased structural and dynamic complexity at the edge of chaos in simple, discrete models (Langton 1990, Kaufmann and Johnsen 1991). Kaufmann (1993) has suggested that systems poised at a critical transition are highly adaptable, a condition that could manifest in abrupt change. The interaction between the fast and slow variables in an economy is characterized by increasing instability, which can lead to fluctuations when these instabilities trigger abrupt change above a critical threshold (Brock and Hommes 1997). Discontinuities can arise endogenously in dynamic systems in the presence of dynamic instabilities in the system (Rosser 2000). 
Fig. 1. The adaptive cycle (Holling 1986); temporal changes in a system proceed through phases of growth $(r)$, conservation $(k)$, release $(\Omega)$, and reorganization $(\alpha)$. The adaptive cycle is an effective model for systems, the levels in a panarchy, and the dynamics of individual systems. Source: Cambridge University Press.

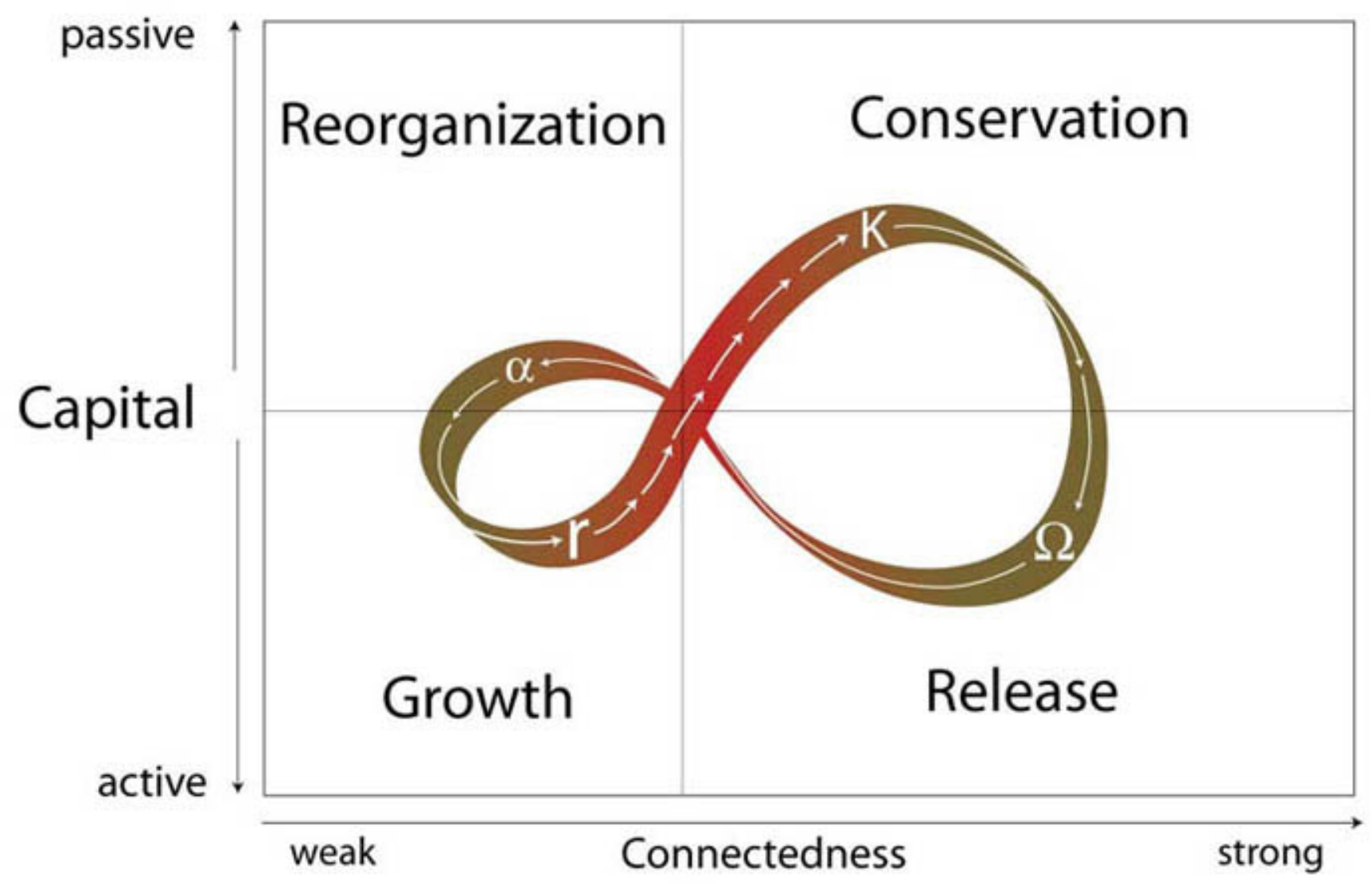

The organization of an economic system depends on the linkages between agents, which change discontinuously via critical transitions within these linkages (Rosser 2003). Beyond this bifurcation point, a greater degree of regional linkage heightens volatility as agents drive the system toward divergent growth trajectories (Rosser 2003). Changes in nonuniform comparative advantages trigger abrupt or smooth changes in urban systems (Dendrinos and Rosser 1992), and social interaction dynamics are inherently nonlinear (Dendrinos 2002). New hierarchical levels can emerge in urban systems via an expansion of trade, lower transportation costs, or changes in the internal structures of cities (Rosser 1994). Nonlinear oscillations can trigger a phase transition and the emergence of a new level in a hierarchy. An emergent level is evidence of discontinuity in the organization of a system (Goldstein 2002), and this new level of organization is a construct of panarchy in complex systems (Gunderson and Holling 2001).

\section{CROSS-SCALE PATTERNS: ECOSYSTEMS}

Evidence for scale-dependent patterns is plentiful in the ecological literature, because ecological processes operate on distinct spatial and temporal scales (Levin 1992). At the same time, species of different sizes and mobility can be influenced by different processes at the same spatial scale (Olff and Ritchie 2002), indicating the cross-scale nature 
Fig. 2. Systems are made up of patterns and processes at discrete scales. The scales present are disconnected, i.e., discontinuous, and these discontinuities are thresholds between scales, i.e., adaptive cycles. A panarchy is a nested set of adaptive cycles. Adapted from Gunderson and Holling (2002). Used with permission from Island Press.

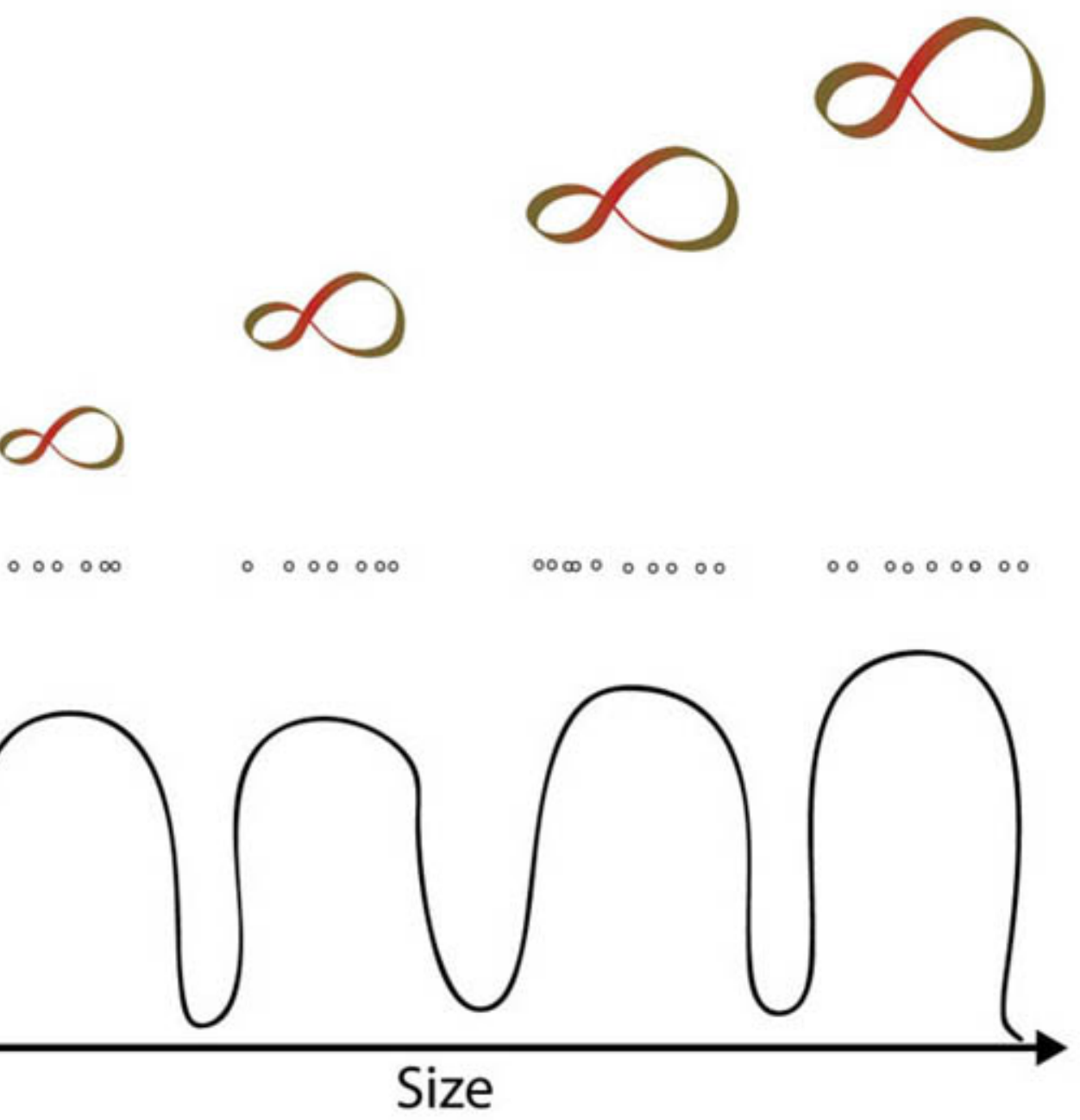

of the processes that shape patterns in ecosystems (Peterson et al. 1998). Evidence of discontinuities in ecosystem data has accumulated quickly over time, forcing a shift from the "ecosystems as continuous systems" paradigm. Oksanen et al. (1979) observed that, in species sequences of wading birds from northern Europe, the size ratios between the closest species were not constant, leading to the formation of gaps. This observation was in disagreement with the idea that the ratios of body mass should be constant as a result of resource competition in areas in which species have achieved the tightest possible packing on a single niche dimension (Hutchinson 1959, Diamond 1972). To explain their results, Oksanen et al. (1979) evaluated three hypotheses and concluded that discontinuities were caused by interspecific aggression modulated by habitat structure. Kolasa (1989) asserted that the structure of the environment is a nested hierarchy of habitat "units," with biotic and abiotic factors sorting biological components into respective levels within the hierarchical structure of the environment. The model showed that the nested hierarchy of habitat units should lead to the clustering of species at discrete scales (Kolasa 1989). 
Although predation can affect body size distribution and the abundance of species, analyses do not support the existence of "trophic trophs" (Holling 1992). Stubblefield et al. (1993) observed that the size distribution of some prey items of the beewolf (Philanthus sanbornii) was multimodal. Among female bees, including both individuals and species, there were three size classes separated by two discontinuities. The authors concluded that diffuse competition within an assemblage favored the formation of size guilds (Stubblefield et al. 1993) because of the absence of multimodality among prey items that did not feed on pollen. This absence suggested that aspects of pollen foraging produce discontinuities.

Experiments involving manipulated sedimentation in intertidal zones and its effects on body size distribution have produced contrasting results. Schwinghamer (1981) originally suggested that troughs in microfaunal body size distributions are caused by differences in sediment particle size. Raffaelli et al. (2000) found that body sizes were conserved when particle size was manipulated, suggesting that microfaunal assemblages have welldefined body size distributions shaped by structural features. Although experimentally altering marine sediment assemblages with size-specific perturbations of organic enrichment and predation caused the densities and relative abundances of invertebrate taxa to shift, there was little change in benthic biomass or the abundance size spectrum, with the result that a multimodal distribution of species was maintained (Raffaelli et al. 2000). Havlicek and Carpenter (2001) compared body mass distributions in a set of experimental lakes and reported that, despite changes in lake nutrient status and species composition, the multimodal body mass distributions of a wide range of species were conserved. Cumming and Havlicek (2002) used a cellular automaton model to evaluate body size distributions for 138 fish species. They found consistent modality in the data and concluded that the structure detected was likely driven by ecological and evolutionary processes. Kamenir et al. (2004) analyzed seasonal and interannual variability in the size structure of phytoplankton of Lake Kinneret, Israel, and found that the assemblage was characterized by size classes separated by gaps. Stead et al. (2005) sampled a range of size fractions of stream benthic metazoans and documented persistent changes in the number and locations of modes in the distribution, indicating that no single factor determines body size distributions. In particular, they rejected the role of energetics as the sole factor shaping the stream community. Stead et al. (2005) claim that breaks in body size distributions indicate an abrupt shift in the scale at which species operate in an environment. A pattern of peaks and troughs persisted regardless of the temporal and spatial variation in the data set (Stead et al. 2005). The three-dimensional structure of habitat provides a strong predictor of the body masses of the species dependent upon that habitat (Gutierrez and Iribarne 2004), and others continue to document a relationship between discontinuities in body size distributions and habitat structure in freshwater fish (Fu et al. 2004) and nekton (Pittman et al. 2004). Robson et al. (2005) argued that studies must once again emphasize habitat structure and body mass to refine the methodology and synthesize results from pattern seeking and mechanistic research.

In addition to research on fish and invertebrates, analyses of the body mass distributions of birds, mammals, and herpetofauna have revealed discontinuous patterns (Restrepo et al. 1997, Lambert and Holling 1998). Restrepo et al. (1997) found that rank-size distributions for frugivorous birds in the neotropical mountains of Colombia were discontinuous. Lambert and Holling (1998) found that mammal body mass distributions in northern Florida and southern California, from the Pleistocene and the present, were discontinuous. More recently, Scheffer and van Nes (2006) used a competition model to demonstrate that modality is an emergent property within the context of coevolution of competitors. They contend that selforganized size classes represent scales of opportunity separated by discontinuities, which are indicative of forbidden zones. Szabo and Meszena (2006) used a resource utilization model to investigate the role of natural selection in scale of perception. Their results conclude that discrete scales of opportunity act as distinct resources and that species with similar perceptions are better at using resources at the same scale.

Allen et al. (1999) and Allen and Saunders (2002, 2006) have demonstrated using empirical evidence that the species invading a landscape, species that are declining or extinct, species that are nomadic, and the species with the greatest fluctuations in time and space are generally close to discontinuities in body mass distributions. These phenomena reflect biotic variability. Invasions and extinctions represent permanent turnover in species composition over time, and nomadic species vary their location 
in both space and time. Allen et al. (1999) used data on herpetofauna, birds, and mammals from the Everglades region of Florida in the United States and found that the edges of size classes were the location for invasions and extinctions, which suggests that the edges of structure may be transition zones between distinct ranges of scale. Using this same data set, Forys and Allen (2002) found that, despite extensive changes in species composition because of extinctions and invasions, functional group richness did not change, nor did redundancy of function across scales. Allen (2006) supported the results of Allen et al. (1999) and extended their results by accounting for unsuccessful invasions in the analysis. Furthermore, the analysis of invasive species by Allen (2006) tested other intrinsic and community theories that could explain the success or failure of invasive species, and the best model incorporated only one variable: proximity to discontinuity in the body mass distribution. Using avifauna data from the Mediterranean-climate region of south-central Australia, Allen and Saunders $(2002,2006)$ found that the edges of size classes were significant predictors of nomadism. D. Wardwell and C. R. Allen (unpublishedmanuscript) have demonstrated that the abundance of species at the edge of body mass distributions is more variable in both time and space. Furthermore, the distribution of generalism is also predicted by size and discontinuities. Larger species are more likely to be generalists than smaller species, but, regardless of size, generalism is nonrandomly but idiosyncratically distributed in relation to discontinuities. These results add further strength to the contention that the edges of size classes are "zones of transition" at the available scales of opportunity.

\section{CROSS-SCALE PATTERNS: URBAN AND ECONOMIC SYSTEMS}

Scale plays a critical role in economic systems as well as in ecosystems. Bessey (2002) asserts that temporal and spatial discontinuities are fundamental elements of system structure. Lederer and Mehta (2005) have demonstrated that the increased scale of technology projects produces increased risk via pressure on the operating leverage of the investment. They assert that scale is typically ignored in most financial analyses, which results in a miscalculation of the effect of scale on value and suboptimal scale decisions. Essentially, the inflexibility of a scale-invariant model results in suboptimal results that could have been improved by considering scale. In economics, temporal scale factors into the structure of decisions, degree of aggregation, strength of relationships, and variables relevant to the particular process (Ramsey and Lampart 1998).

Discontinuous patterns have been found in international economic data (Summers and Heston 1991), in which the variable of interest was the gross domestic product (GDP) per capita measured for 120 countries over a $30-\mathrm{yr}$ time frame. A discontinuous distribution was found to persist over time, and the overall structure bound the trajectories of growth for individual countries within the data set. Cross-country growth exhibits behavior that is best characterized through convergence clubs, in which the economy of the country is auto-correlated with the economies of other countries with similar growth, resulting in multiple steady states (Durlauf and Johnson 1995). Economic growth can manifest into multiple stable steady states, i.e., convergence clubs, through differential growth rates (Durlauf 1996). The assumption that complex systems are evolving to a single steady state, as opposed to systems characterized by multiple steady states, can lead to collapse in ecosystems (Peterson et al. 2003) and economic systems (Brock and Hommes 1997). Di Guilmi et al. (2003) identified power-law scaling in world income distribution, i.e., GDP per capita, but only for the range between the 30th and 85th percentiles. This finding implies that, at a minimum, the lower tail and the upper tail of the distribution are operating at different scales than the middle of the distribution.

Garmestani et al. (2005) analyzed time series of citysize data from the southwestern region of the United States and found that the distributions were discontinuous, as theorized by Bessey (2002). Garmestani et al. (2008a) conducted a replicate analysis of the one conducted by Garmestani et al. in 2005 and also documented persistent discontinuities in the rank-size time-series city data. Although a city's size-class status may change over time, these changes did not alter the persistent nature of discontinuities in the city size distributions of these regions. Further, changes in size-class status did not result in continuous distributions.

Bessey (2002) identified departures from a ranksize characterization (Zipf' Law; Zipf 1949) of the city size data in the southeastern region of the United States. Using Bessey's data, Garmestani et al. (2007) performed a statistical hypothesis test upon 
rank-size city data from the southeastern region of the United States under the assumptions of Gibrat's Law (Gibrat 1957). Zipf's Law manifests when all central places in an urban hierarchy have sizeinvariant growth rates. Thus, if Gibrat's Law is not satisified, Zipf's Law cannot be satisfied. Garmestani et al. (2007) found that growth rates differed by city size, in contrast to the distribution expected if Gibrat's Law held for this data set. On a regional level, the results indicated that city growth was not driven by small, random growth forces. Rather, growth was correlated with size, with smaller cities exhibiting higher growth rates and larger cities exhibiting lower growth rates (Garmestani et al. 2007). The results reported in Garmestani et al. (2007) indicated that discrete size classes in city size distributions emerged as a result of size-dependent growth at the available scales of opportunity within urban systems.

The results of Garmestani et al. (2008b) are remarkably similar to those of Crawley and Harral (2001). In an analysis of species richness and spatial scale, Crawley and Harral (2001) found different scaling relationships at different scales. They characterized different slopes in the species-area relationships at different scales as evidence of scaledependent processes. Garmestani et al. (2008b) tested the overall city size distributions for the southeastern and southwestern United States (1990), as well as the individual size classes previously identified in Garmestani et al. (2008a) for power-law behavior. Power laws provided fits for overall city size distribution in the southeastern and southwestern regions of the United States. However, overall city size distribution in the southeastern region of the United States exhibited a departure from power-law behavior in the upper tail. In addition, the cities in the southeastern region self-organized into three discrete size classes, and the southwestern region was self-organized into six size classes, each of which is also well described by power laws with differing slopes and intercepts. In the southeastern region of the United States, there was greater variability in the sizes of small cities when compared to the size class for large cities. With respect to the different power-law fits for the individual size classes, the overall power law for the distribution did not capture evidence of the processes affecting city size at a finer scale of analysis, i.e., the individual size classes. Different power-law fits for individual size classes support the proposition that different processes, e.g., growth rates, act upon cities at different scales. Garmestani et al. (2008b) interpreted the differences in the power-law fits in the city size distributions as the manifestation of variable growth dynamics dependent upon city size. Complex systems can manifest multiple stable states (Gunderson et al. 2002), and size classes are evidence of multiple stable states within a system, whereas the powerlaw fits for each size class are indicative of the discrete ranges of scale at which cities are governed by similar processes.

Garmestani et al. (2006) examined company size distributions for manufacturing firms in the state of South Carolina, USA. They conducted discontinuity analysis within the context of resilience and demonstrated that firms were clustered in size classes within industrial sectors. Resilience is the ability of a system to withstand shocks and remain within a basin of attraction (Holling 1973). The functional richness within a size class is an aspect of resilience (Allen et al. 2005). In characterizing the resilience of a system, Garmestani et al. (2006) followed the cross-scale resilience model of Peterson et al. (1998). The model proposed that the determination of discontinuities and the quantification of the function of firms within and across size classes provided a measure of the resilience of a system (Allen et al. 2005). Garmestani et al. (2006) characterized the cross-scale resilience model proposed by Peterson et al. (1998) combined with the coefficient of variation of the employment trend for the data as a plausible measure of resilience within an industrial sector. The results indicated that manufacturing industries with greater functional richness spread across size classes suffered less volatility in employment. The ability of small and large firms to adapt to variability in their "environment" without adding or shedding members suggested that economic resilience was enhanced when firms of different sizes emerged or were encouraged to emerge within industries.

\section{DISCUSSION}

Within complex systems, patterns measured at small scales do not necessarily hold at larger scales, while processes dominating at small scales do not necessarily prevail at large scales (Schneider 2001). Sandpile models have been used to capture evidence of the adaptive cycle in complex systems (Bak 1996), but, unlike physical systems, complex living systems transform, invent new forms, and endogenously control potential as it accumulates 
(Holling and Gunderson 2001). Physical systems such as sandpiles do not have the capacity to evolve; living systems do (Holling and Gunderson 2001). Although systems such as ecosystems, economic systems, and urban systems are complex systems, the processes driving patterns in these systems are not the same (Adger 2000). For example, city growth rates have no effect on structuring processes in ecosystems but appear to be critical to urban systems.

Understanding regime shifts and what drives them has become critical to gaining insights on system resilience. To date, analysis of complex systems has been focused on regime shifts and multiple regimes at the system level. We have reviewed the research on discontinuities between adaptive cycles, the detection of those discontinuities, and the subsequent patterns or panarchy in complex systems. Panarchy is theory, whereas discontinuity analysis allows us to reveal the panarchy and interpret the pattern. The weight of the evidence from discontinuity research indicates that the same system behaviors operate at a finer scale. In essence, complex systems exhibit multiple dynamic regimes within systems in addition to the observed behavior at larger scales, and the discrete size classes observed in the rank-size function of variables in complex systems are evidence of these multiple dynamic regimes within systems. These size classes then are "scales of opportunity" at which the selforganization of system dynamics allows for existence. Within the context of resilience (Holling 1973), complex systems are more resilient when the threshold between a given dynamic regime and an alternate regime is higher (Ives and Carpenter 2007). To the best of our knowledge, discontinuity analysis provides the only established method to detect scales of structure in complex systems (Stow et al. 2007).

\section{CONCLUSION}

In this paper, we have reviewed and synthesized the research focused on discontinuities in ecological systems and similar patterns in urban and social systems. These systems reflect the presence of adaptive cycles across the scales of a panarchy. Panarchy is a theoretical construct, and, because processes, structure, and variables appear to operate at discrete ranges of scale, discontinuity analysis allows us to detect scale-specific patterns in complex systems. Unlike the top-down control envisioned in traditional hierarchies, the connectivity between the adaptive cycles in a panarchy can be from levels above or below. The levels in a panarchy are not static states, but rather adaptive cycles that are interconnected to other adaptive cycles in the panarchy. Each cycle operates over a discrete range of scale in both time and space and is connected to adjacent levels. A system's resilience depends on the interactions between structure and dynamics at multiple scales. Although there has been a significant amount of research conducted on the subject of resilience, this paper provides the link to empirical evidence from ecological, urban, and economic systems that helps explain how resilience is generated in complex systems.

Responses to this article can be read online at: http://www.ecologyandsociety.org/voll4/iss1/art15/ responses/

\section{Acknowledgments:}

Support was provided by the James S. McDonnell Foundation 21st Century Research Award/Studying Socio-ecological Systems. The Nebraska Cooperative Fish and Wildlife Research Unit is jointly supported by a cooperative agreement between the U.S. Geological Survey, the Nebraska Game and Parks Commission, the University of Nebraska-Lincoln, the U.S. Fish and Wildlife Service, and the Wildlife Management Institute. This manuscript was improved by comments from H. Cabezas, D.E. Campbell, and M.E. Hopton.

\section{LITERATURE CITED}

Adger, W. N. 2000. Social and ecological resilience: Are they related? Progress in Human Geography 24:347-364.

Allen, C. R. 2006. Predictors of introduction success in the south Florida avifauna. Biological Invasions 8:491-500.

Allen, C. R., L. Gunderson, and A. R. Johnson. 2005. The use of discontinuities and functional groups to assess relative resilience in complex systems. Ecosystems 8:958-966. 
Allen, C. R., E. A. Forys, and C. S. Holling. 1999. Body mass patterns predict invasions and extinctions in transforming landscapes. Ecosystems 2:114-121.

Allen, C. R., and D.A. Saunders. 2002. Variability between scales: predictors of nomadism in birds of an Australian Mediterranean-climate ecosystem. Ecosystems 5:348-359.

Allen, C. R., and D. A. Saunders. 2006. Multimodel inference and the understanding of complexity, discontinuity and nomadism. Ecosystems 9:694-699.

Bak, P. 1996. How nature works: the science of selforganized criticality. Copernicus Press, New York, New York, USA.

Bak, P., C. Tang, and K. Wiesenfeld. 1988. Selforganized criticality. Physical Review A 38:364-374.

Bessey, K. M. 2002. Structure and dynamics in an urban landscape: toward a multiscale view. Ecosystems 5:360-375.

Bonabeau, E. 1998. Social insect colonies as complex adaptive systems. Ecosystems 1:437-443.

Brock, W.A., and C.A. Hommes. 1997. A rational route to randomness. Econometrica 65:1059-1095.

Crawley, M. J., and J. E. Harral. 2001. Scale dependence in plant biodiversity. Science 291:864-868.

Crutchfield, J. P. 1994. The calculi of emergence: computation, dynamics, and induction. Physica $D$ 75:11-54.

Cumming, G. S., and T. D. Havlicek. 2002. Evolution, ecology, and multimodal distributions of body size. Ecosystems 5: 705-711.

Dendrinos, D. S. 2002. Stimulus, expectations, desires and response strategies: the building blocks of nonlinear interaction dynamics. Discrete Dynamics in Nature and Society 7:133-149.

Dendrinos, D. S., and J. B. Rosser. 1992. Fundamental issues in nonlinear urban population dynamic models: theory and a synthesis. Annals of Regional Science 26:135-145.
Di Guilmi, C., E. Gaffeo, and M. Gallegati. 2003. Power law scaling in the world income distribution. Economics Bulletin 15:1-7.

Diamond, J. M. 1972. Biogeographic kinetics: estimation of relaxation times for avifaunas of Southwest Pacific Islands. Proceedings of the National Academy of Sciences 69:3199-3203.

Durlauf, S. N. 1996. On the convergence and divergence of growth rates. Economic Journal 106:1016-1018.

Durlauf, S. N., and P. A. Johnson. 1995. Multiple regimes and cross-country growth behaviour. Journal of Applied Econometrics 10:365-384.

Fath, B. D., H. Cabezas, and C. W. Pawlwoski. 2003. Regime changes in ecological systems: an information theory approach. Journal of Theoretical Biology 222:517-530.

Folke, C., S. R. Carpenter, B. Walker, M. Scheffer, T. Elmqvist, L. Gunderson, and C. S. Holling. 2004. Regime shifts, resilience and biodiversity in ecosystem management. Annual Review of Ecology and Systematics 35:557-581.

Forys, E. A., and C. R. Allen. 2002. Functional group change within and across scales following invasions and extinctions in the Everglades ecosystem. Ecosystems 5:339-347.

Fu, C., J. Wu, X. Wang, G. Lei, and J. Chen. 2004. Patterns of diversity, altitudinal range and body size among freshwater fishes in the Yangtze River basin, China. Global Ecology and Biogeography 13: 543-552.

Garmestani, A. S., C. R. Allen, and K. M. Bessey. 2005. Time-series analysis of clusters in city size distributions. Urban Studies 42:1507-1515.

Garmestani, A. S., C. R. Allen, J. D. Mittelstaedt, C. A. Stow, and W. A. Ward. 2006. Firm size diversity, functional richness and resilience. Environment and Development Economics 11:533-551.

Garmestani, A. S., C. R. Allen, C. M. Gallagher, and J. D. Mittelstaedt. 2007. Departures from Gibrat's Law, discontinuities and city size distributions. Urban Studies 44:1997-2007. 
Garmestani, A. S., C. R. Allen, and K. M. Bessey. 2008a. Discontinuities in urban systems: comparison of regional city-size structure in the United States. Pages 136-164 in C. R. Allen and C. S. Holling, editors. Discontinuities in ecosystems and other complex systems. Columbia University Press, New York, New York, USA.

Garmestani, A. S., C. R. Allen, and C. M. Gallagher. 2008b. Power laws, discontinuities and regional city size distributions. Journal of Economic Behavior \& Organization 68:209-216.

Gibrat, R. 1957. On economic inequalities. International Economic Papers 7: 53-70.

Goldstein, J. 2002. The singular nature of emergent levels: suggestions for a theory of emergence. Nonlinear Dynamics, Psychology, and Life Sciences 6:293-309.

Gunderson, L., and C. S. Holling. 2001. Panarchy: understanding transformations in systems of humans and nature. Island Press, Washington, D.C., USA.

Gunderson, L. H., L. Pritchard, Jr., C. S. Holling, C. Folke, and G. D. Peterson. 2002. A summary and synthesis of resilience in large-scale systems. Pages 249-261 in L. H. Gunderson and L. Pritchard, Jr., editors. Resilience and the behavior of largescale systems. Island Press, Washington, D.C., USA.

Gutierrez, J. L. and O. O. Iribarne. 2004. Conditional responses of organisms to habitat structure: an example from intertidal mudflats. Oecologia 139: 572-582.

Hartvigsen, G., A. Kinzig, and G. Peterson. 1998. Use and analysis of complex adaptive systems in ecosystem science: overview of special section. Ecosystems 1:427-430.

Havlicek, T., and S. R. Carpenter. 2001. Pelagic species size distributions in lakes: Are they discontinuous? Limnology and Oceanography 46:1021-1033.

Holling, C. S. 1973. Resilience and stability of ecological systems. Annual Review of Ecology and Systematics 4:1-23.
Holling, C. S. 1986. The resilience of terrestrial ecosystems: local surprise and global change. Pages 292-317 in W. C. Clark and R. E. Munn, editors. Sustainable development of the biosphere. Cambridge University Press, Cambridge, UK.

Holling, C. S. 1992. Cross-scale morphology, geometry, and dynamics of ecosystems. Ecological Monographs 62:447-502.

Holling, C. S., and L. H. Gunderson. 2001. Resilience and adaptive cycles. Pages 63-102 in L. H. Gunderson and C. S. Holling, editors. Panarchy: understanding transformations in systems of humans and nature. Island Press, Washington, D. C., USA.

Hutchinson, G. E. 1959. Homage to Santa Rosalia, or why are there so many kinds of animals? American Naturalist 93:245-249.

Ives, A. R., and S. R. Carpenter. 2007. Stability and diversity of ecosystems. Science 317:58-62.

Kamenir, Y., Z. Dubinsky, and T. Zohary. 2004. Phytoplankton size structure stability in a mesoeutrophic subtropical lake. Hydrobiologia 520: 89-104.

Kauffman, S. A. 1993. The origins of order: selforganization and selection in evolution. Oxford University Press, Oxford, UK.

Kauffman, S. A., and S. Johnsen. 1991. Coevolution to the edge of chaos: coupled fitness landscapes, poised states, and coevolutionary avalanches. Journal of Theoretical Biology 149:467-505.

Kolasa, J. 1989. Ecological systems in hierarchical perspective: breaks in community structure and other consequences. Ecology 70:36-47.

Lambert, W. D., and C. S. Holling. 1998. Causes of ecosystem transformation at the end of the Pleistocene: evidence from mammal body-mass distributions. Ecosystems 1:157-175.

Langton, C. G. 1990. Computation at the edge of chaos: phase transitions and emergent computation. Physica D 42:12-37. 
Lederer, P. J., and T. D. Mehta. 2005. Economic evaluation of scale-dependent technology investments. Production and Operations Management 14:21-34.

Levin, S. A. 1992. The problem of pattern and scale in ecology. Ecology 73:1943-1967.

Levin, S. A. 1998. Ecosystems and the biosphere as complex adaptive systems. Ecosystems 1:431-436.

Loreto, V., L. Pietronero, A. Vespignani, and S. Zapperi. 1995. Renormalization group approach to the critical behavior of the forest-fire model. Physical Review Letters 75:465-468.

Ludwig, D., B. H. Walker, and C. S. Holling. 2002. Models and metaphors of sustainability, stability, and resilience. Pages 21-48 in L. H. Gunderson and L. Pritchard, Jr., editors. Resilience and the behavior of large-scale systems. Island Press, Washington, D.C., USA.

Oksanen, L., S. D. Fretwell, and O. Orvinen. 1979. Interspecific aggression and the limiting similarity of close competitors: the problem of size gaps in some community arrays. American Naturalist 114: 117-129.

Olff, H., and M. E. Ritchie. 2002. Fragmented nature: consequences for biodiversity. Landscape and Urban Planning 58:83-92.

Peterson, G. D. 2002. Contagious disturbance, ecological memory, and the emergence of landscape pattern. Ecosystems 5:329-338.

Peterson, G. D., C. R. Allen, and C. S. Holling. 1998. Ecological resilience, biodiversity and scale. Ecosystems 1:6-18.

Peterson, G. D., S. R. Carpenter, and W.A. Brock. 2003. Uncertainty and the management of multistate ecosystems: an apparently rational route to collapse. Ecology 84:1403-1411.

Pittman, S. J., C. A. McAlpine, and K. M. Pittman. 2004. Linking fish and prawns to their environment: a hierarchical landscape approach. Marine Ecology Progress Series 283: 233-254.

Raffaelli, D., S. Hall, C. Emes, and B. Manly. 2000. Constraints on body size distributions: an experimental approach using a small-scale system. Oecologica 122:389-398.
Ramsey, J., and C. Lampart. 1998. The decomposition of economic relationships by time scale using wavelets: expenditure and income. Studies in Nonlinear Dynamics \& Econometrics 3:23-42.

Restrepo, C., L.M. Renjifo, and P.Marples. 1997. Frugivorous birds in fragmented neotropical montane forests: landscape pattern and body mass distribution. Pages 171-189 in W. F. Laurance, R. O. Bierregaard, and C. Moritz, editors. Tropical forest remnants: ecology, management and conservation of fragmented communities. University of Chicago Press, Chicago, Illinois, USA.

Robson, B. J., L. A. Barmuta, and P. G. Fairweather. 2005. Methodological and conceptual issues in the search for a relationship between animal body-size distributions and benthic habitat architecture. Marine and Freshwater Research 56:1-11.

Rosser, J. B. 1994. Dynamics of emergent urban hierarchy. Chaos, Solitons and Fractals 4:553-561.

Rosser, J. B. 2000. A new perspective on economic discontinuity. Journal of Management and Economics 4:4.

Rosser, J. B. 2003. A reconsideration of the role of discontinuity in regional economic models. Chaos, Solitons and Fractals 18:451-462.

Scheffer, M., and S. R. Carpenter. 2003. Catastrophic regime shifts in ecosystems: linking theory to observation. Trends in Ecology and Evolution 18:648-656.

Scheffer, M., S. R. Carpenter, J. A. Foley, C. Folke, and B. Walker. 2001. Catastrophic shifts in ecosystems. Nature 413:591-596.

Scheffer, M., and E. H. van Nes. 2006. Selforganized similarity, the evolutionary emergence of groups of similar species. Proceedings of the National Academy of Sciences 103:6230-6235.

Schneider, D. C. 2001. The rise of the concept of scale in ecology. BioScience 51:545-553.

Schwinghamer, P. 1981. Characteristic size distributions of integral benthic communities. Canadian Journal of Fisheries and Aquatic Sciences 38:1255-1263. 
Stead, T. K., J. M. Schmid-Araya, P. E. Schmid, and A. G. Hildrew. 2005. The distribution of body size in a stream community: one system, many patterns. Journal of Animal Ecology 74:475-487.

Stow, C., C. R.Allen, and A. S. Garmestani. 2007. Evaluating discontinuities in complex systems: toward quantitative measures of resilience. Ecology and Society 12(1): 26. [online] URL: http://www.e cologyandsociety.org/vol12/iss 1/art26/.

Stubblefield, J. W., J. Seger, J. W. Wenzel, and M. M. Heisler. 1993. Temporal, spatial, sex-ratio and body-size heterogeneity of prey species taken by the beewolf Philanthus sanbornii, Hymenoptera: Sphecidae. Philosophical Transactions of the Royal Society of London Series B 339:397-423.

Summers, R., and A. Heston. 1991. The Penn World Table (Mark 5): an expanded set of international comparisons, 1950-1988. Quarterly Journal of Economics 106:327-368.

Szabo, P., and G. Meszena. 2006. Spatial ecological hierarchies: coexistence on heterogeneous landscapes via scale niche diversification. Ecosystems 9:1009-1016.

Zipf, G. K. 1949. Human behaviour and the principle of least effort: an introduction to human ecology. Addison-Wesley, Cambridge, Massachusetts, USA. 